\section{John J. Bergan, 1927-2014}

John Bergan was born on August 4, 1927 and graduated in Medicine at the University of Indiana in 1954. He spent the residency in surgery at the Chicago Wesley Memorial Hospital and in 1960 was certified in the American Board of Surgery. The body of his academic career took place at the North Western University in Chicago, where he devoted himself to vascular surgery and also to its applications in transplantation surgery. Scrolling through the records of the North-Western Registry, it turns out that John performed his first kidney transplant as the first operator in 1964, and was Director of the program till 1976.

However, for the European phlebologist John was the ambassador of Phlébologie in the United States of America. Two were his key meetings in the field. The first was with Geza de Takats, a forerunner of the modern Phlebology, who operated for long time in Chicago. John was in strong contact with this Mentor, to the point that he wrote the obituary on Surgery in 1986, when he died. The second was the stellar conjunction with James S. T.
Yao at the NorthWestern University. Together they released the first complete text-book of Phlebology in the United States, Venous Problems, at the end of the 70's. In the 80's, he was one of the Founding Fathers of the American Venus forum, at the famous first meeting at the hotel of Coronado, and, subsequently, President. But he also served as President the American College of Phlebology. This because was an eclectic and multi-core phlebologist, equally interested and curious about the new features in outpatient practice, as well as in cutting-edge research applied to the venous system.

The last years of his academic career were actively spent in a climate much more favourable compared to Illinois, at the University of California San Diego, in La Jolla, where he continued to work and publish on veins.

Few years ago Claude Franceschi and me taught venous haemodynamics, at a course organised in Arizona by our common friend Nick Morrison. I will never forget that he sat smiling and enthusiastic between the desks of the trainees. He was a giant in Phlebology, but always curious about new things, and was not afraid to get into the game.

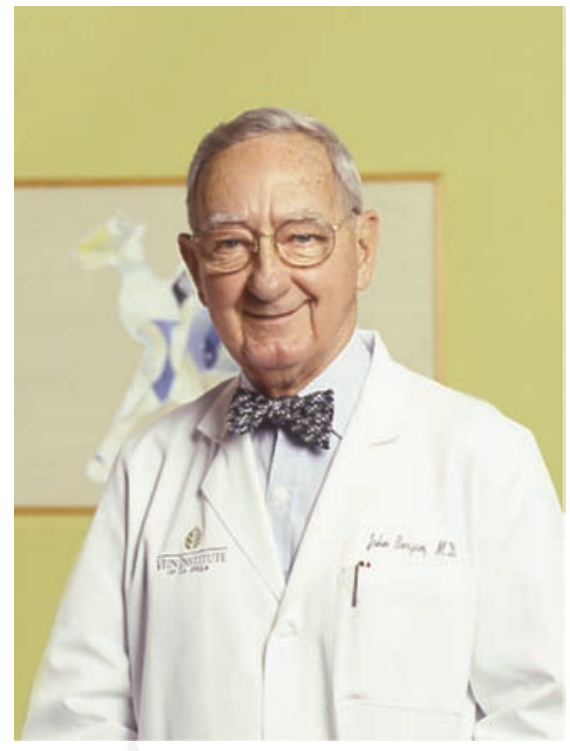

John was a true gentleman, with whom it was nice to have a discussion or even dispute a controversy, thanks to his unforgettable elegance.

Paolo Zamboni University of Ferrara, Italy 